\title{
Living in a dangerous world: the shaping of behavioral profile by early environment and 5-HTT genotype
}

\author{
Rebecca S. Heiming 1,2, Friederike Jansen 1,2, Lars Lewejohann ${ }^{1,2}$, Sylvia Kaiser, ${ }^{1,2}$, Angelika Schmitt ${ }^{3}$, \\ Klaus Peter Lesch ${ }^{3}$ and Norbert Sachser ${ }^{1,2 *}$ \\ 'Department of Behavioural Biology, University of Muenster, Muenster, Germany \\ 2 Otto Creutzfeldt Center for Cognitive and Behavioral Neuroscience, University of Muenster, Muenster, Germany \\ ${ }^{3}$ Molecular and Clinical Psychobiology, Department of Psychiatry, Psychosomatics and Psychotherapy, University of Wuerzburg, Wuerzburg, Germany
}

\section{Edited by:}

Larry J. Young, Emory University

School of Medicine, USA; Yerkes

National Primate Research Center,

USA

\section{Reviewed by:}

Alexa H. Veenema, University of Massachusetts, USA

Chadi Touma, Max Planck Institute of

Psychiatry, Germany

*Correspondence:

Norbert Sachser, Department of Behavioral Biology, University of

Muenster, Badestraße 13, D-48149

Muenster, Germany.

e-mail: sachser@uni-muenster.de
Anxiety and anxiety disorders are influenced by both, environmental and genetic factors. One genetic factor under scrutiny for anxiety disorders is the genetically encoded variation of the serotonin transporter (5-HTT). The aim of this study was to elucidate the effects of a threatening environment during early phases of life on anxiety-like (ANX) and exploratory behavior (EXP) in adult mice, varying in serotonin transporter (5-HTT) genotype. For this purpose, pregnant and lactating $5-\mathrm{HTT}+/-$ dams were repeatedly exposed to olfactory cues of unfamiliar adult males by introducing small amounts of soiled bedding to their home cage. These stimuli signal the danger of infanticide and simulate a threatening environment. Control females were treated with neutral bedding. The offspring $(5-\mathrm{HTT}+/+$, $+/-,-1-)$ were examined for their ANX and EXP. The main results were: (1) a main effect of genotype existed, with 5-HTT -/- showing higher levels of ANX and lower levels of EXP than $5-\mathrm{HTT}+/-$ and wildtypes. (2) When mothers had lived in a threatening environment, their offspring showed increased ANX and reduced EXP compared to controls. (3) These effects were most pronounced in 5-HTT -/- mice. By applying a new ecologically relevant paradigm we conclude: If $5-\mathrm{HTT}+/-$ mothers live in a threatening environment during pregnancy and lactation, their offspring behavioral profile will, in principle, be shaped in an adaptive way preparing the young for an adverse environment. This process is, however, modulated by 5-HTT genotype, bearing the risk that individuals with impaired serotonergic neurotransmission (5-HTT -/-) will develop an exaggerated, potentially pathological level of anxiety from gene $\times$ environment interactions.

Keywords: adaptation, anxiety, behavioral profile, exploration, gene $\times$ environment interaction, maternal effects, mice, serotonin transporter

\section{INTRODUCTION}

Anxiety is a common emotional phenomenon and normally emerges as an adaptive response to various stressors (Clément et al., 2002). However, when occurring excessively and without any adequate elicitor, anxiety-like emotions have lost their adaptive value. In its pathological form, anxiety can severely interfere with normal life and has been classified into various forms of disorders (Belzung and Griebel, 2001; Gross and Hen, 2004). A growing body of evidence indicates that anxiety as well as anxiety disorders can be influenced by both environmental as well as genetic factors (Clément et al., 2002; Gross and Hen, 2004; Lesch, 2004).

Concerning environmental influence, the risk for emotional disorders is increased in individuals who experienced stressful life events during their childhood (Brown et al., 1999; Heim and Nemeroff, 2001). In line with these findings, experiences during prenatal and early postnatal life influence the emotionality of rodents and consequently their future behavior persisting for the lifespan (Champagne and Curley, 2005; Kaiser and Sachser, 2005; Weinstock, 2005; Seckl, 2008). For instance the experience of prenatal stress can lead to increased anxiety-like behavior (Vallée et al., 1997; Kofman, 2002; Maccari et al., 2003; Weinstock, 2008). Such fine-tuning of fetal and early juvenile physiology and behavior by the environment is evolutionary conserved and therefore apparently important (Seckl, 2004). Alterations in behavioral profile caused by specific experiences in early life were suggested to represent adaptive maternal effects, meaning that the mothers adjust their offspring to the prevailing environment (Kaiser and Sachser, 2005, 2009).

Concerning genetic factors, one mediator for susceptibility to anxiety disorders is the genetically encoded variation of the serotonin transporter (5-HTT) (Lesch et al., 1996). The human 5-HTT gene contains a repeat length polymorphism in the upstream regulatory region: the short variant is associated with a lower transcriptional efficiency as compared to the long gene variant, resulting in a reduced amount of 5-HTT proteins. The 5-HTT is one key regulator of serotonergic neurotransmission, transporting serotonin (5-HT) from the synaptic cleft back into the presynaptic neuron and thereby terminating the serotonergic signal transmission. Serotonin is produced in brainstem raphe nuclei and is widely distributed throughout the brain. 5-HT signaling is a major modulator of emotional behavior and a central role of the 5-HTT in the control of social behavior has been suggested (Canli 
and Lesch, 2007). Furthermore, 5-HT is an important regulator of morphogenetic activities during early brain development and 5-HT system homeostasis is critical to the genesis, differentiation and maturation of neuronal cells (Lesch and Merschdorf, 2000; Lesch and Gutknecht, 2005). Individuals carrying at least one copy of the short 5-HTT gene variant display higher levels of neuroticism and harm-avoidance (Lesch et al., 1996) as well as a higher trait anxiety (Schinka et al., 2004) than homozygous carriers of the long variant. Consistently, 5-HTT knockout mice, which exhibit either reduced or completely absent 5-HTT expression (Bengel et al., 1998), demonstrate a range of behavioral and endocrine abnormalities that resemble symptoms of mood and anxiety disorders in humans (Holmes et al., 2003a,b; Lesch, 2005; Zhao et al., 2006; Murphy and Lesch, 2008). Given the advantageous ability to control genetic background and environmental circumstances in rodent studies, the 5-HTT knockout mouse provides a valuable model system to study how genetic factors interact with environmental adversity in the development of behavioral profile, in particular anxiety-related traits (Holmes et al., 2003b).

There is increasing evidence that gene $\times$ environment interactions play a major role in shaping the etiology of anxiety disorders and depression. For example, humans with two copies of the short 5-HTT allele suffer an increased risk of depression, but only when they have experienced adverse life events (Caspi et al., 2003; but see also Risch et al., 2009). Rhesus monkeys carrying the low-functioning orthologue of the 5-HTT gene are not only more anxious but also seem to be more susceptible to behavioral pathology when confronted with chronic adversity (Spinelli et al., 2007). After the experience of low maternal care, heterozygous 5-HTT knockout mice show a more pronounced increase of anxiety-related behavior than wildtypes (Carola et al., 2008). However, exposure to repeated electric footshock in the second postnatal week failed to modify the altered phenotypes of 5-HTT knockout mice (Carroll et al., 2007). Possibly, the confrontation with electric footshock does not adequately resemble the adverse life events which may lead to depression in humans with a low 5-HTT expression (Caspi et al., 2003). It could be argued that adverse early life experience should preferably be modeled using an ecologically relevant paradigm.

Therefore, in the present study species relevant adverse environmental influences were applied to simulate a threatening habitat for a female mouse and her pups. Specifically, pregnant and lactating females were exposed to the olfactory cues of unfamiliar adult males, which indicate the risk of infant killing (vom Saal and Howard, 1982; Elwood and Kennedy, 1991; Perrigo et al., 1993; Weber and Olsson, 2008). Unfamiliar male odor cues may even lead to pregnancy disruption shortly after fertilization (deCatanzaro et al., 1996, 2006); a phenomenon known as "Bruce effect" (Bruce, 1959, 1960). By applying these species specific adverse stimuli we sought to create a paradigm with increased relevance, particularly from an ethological point of view.

We hypothesized that this modeling of a dangerous environment during early life would influence the offspring behavioral profile significantly, leading to increased anxiety-like behavior and reduced exploratory locomotion. We further hypothesized that the effects of this adverse environment on behavior would be modulated by 5-HTT genotype, with 5-HTT knockout mice being more responsive than wildtypes.

\section{MATERIALS AND METHODS ANIMALS AND GENERAL HOUSING CONDITIONS}

The present experiment was performed with serotonin transporter (5-HTT) knockout mice (Bengel et al., 1998). Homozygous (-/-) and heterozygous (+/-) 5-HTT knockout mice as well as their wildtype littermates $(+/+)$ were obtained by heterozygote crosses. All mice were housed in transparent standard Macrolon cages type III $(38 \mathrm{~cm} \times 22 \mathrm{~cm} \times 15 \mathrm{~cm})$ with sawdust as bedding material (Allspan, Höveler GmbH \& Co.KG, Langenfeld, Germany) and food and water provided ad libitum. The housing room was maintained at a $12 \mathrm{~h} \mathrm{light/dark} \mathrm{cycle} \mathrm{(lights} \mathrm{on} \mathrm{at} 0700$ hours) at a temperature of $22 \pm 3^{\circ} \mathrm{C}$.

The presented work complies with current regulations covering animal experimentation in Germany. The experiments were approved by the competent local authority as well as by the "Animal Welfare Officer" of the University of Muenster.

\section{OLFACTORY STIMULATION OF MOTHERS}

The estrous stages of 19 healthy virgin female 5-HTT +/- mice were determined by examining their vaginal smears. The smears were sampled by gently sweeping some smear off the interior of the vagina with a small plastic loop and the sample was diluted in a drop of tab water on a microscope glass slide. Subsequently, the smears were examined under a microscope (magnification: $100 \times$ ) and the cycle phases identified according to the characterization of Allen (Allen, 1922). As soon as the females were proestrous or in an early stage of estrous, they were each mated with an adult 5 -HTT +/- male (experimental day 1). On experimental day 5 the males were removed from the cage and the females were housed singly during gestation. After giving birth they were housed together with their offspring. During pregnancy and lactation 10 of the mothers were treated with neutral bedding (neutral bedding treatment, NB) and 9 of the mothers were olfactorily stimulated with bedding stemming from the cages of unfamiliar adult males of the strains NMRI (three males) and TgCRND8 (four males) alternately (unfamiliar male bedding treatment, UMB). For the treatment $220 \mathrm{ml}$ of the respective bedding material was inserted into the cage of the female in the corner opposite of the nest and left there until the next cage change. Cages were cleaned once a week, except in the period from 1 day before to 2 days after the birth of the pups. The mothers were treated every $2-3$ days in the morning, starting on experimental day 8 ; a time when the probability of inducing pregnancy disruption was already relatively low (Chung et al., 1997). The dams received five treatments in the gestation period and two to five treatments during lactation (due to a high mortality of the dams the number of postnatal treatments was reduced in the course of the experiment in both NB and UMB females in the same way).

During the first and the fifth treatment the females' latency to enter the quarter of the cage where the bedding had been placed was measured as well as the time they spent there during the $5 \mathrm{~min}$ following the treatment.

\section{EFFECTS ON THE OFFSPRING}

After weaning at age of 22 days the control and experimental mice were individually marked with fur cuts and placed in unisex sibling groups of two to five animals. Individuals without any littermates 
of the same gender were housed together with mice of the same age and sex. Altogether $36 \mathrm{NB}$ males $(6+/+, 19+/-, 11-/-), 28$ NB females $(13+/+, 9+/-, 6-/-), 34$ UMB males $(10+/+, 17+/-$, $7-/-)$ and 19 UMB females $(7+/+, 5+/-, 7-/-)$ were weaned and subsequently investigated.

Between postnatal days $50 \pm 1$ and $59 \pm 3$ the offspring were tested for their anxiety-like and exploratory behavior by means of the elevated plus maze (EPM) test, dark light test (DL) and open field (OF) test. The test procedures were performed between 0900 and 1100 hours. After each test session the apparatuses were cleaned with $70 \%$ ethanol. All experiments were performed by the same experimenter who was blind to the genotypes of the mice.

Since the applied behavioral tests are all based on the exploratory locomotion of the mice, some of the measured parameters can not unequivocally be interpreted as indicating the anxiety-related approach avoidance conflict, but are also influenced by the basal locomotor activity and exploratory drive of the animals (Lister, 1990; Holmes, 2001). Lesch (2005) states that anxiety-like behavior often appears to contrast with exploratory behavior, which indicates that avoidance and curiosity or novelty seeking are biologically related and share common physiological mechanisms. Thus, a strong anxiety-like phenotype would be automatically associated with a low exploratory drive. In this case the intermingling of exploration and anxiety in exploration-based tests for anxiety-like behavior would not affect the interpretation of genotype or treatment effects, since both anxiety and exploration would be influenced. For clarity, we tried to classify the different testing parameters according to their significance for anxiety-like or exploratory behavior: We regard the parameters percentage of time spent on open arms (EPM), percentage of entries into open arms (EPM), latency to enter light compartment (DL), percentage of time spent in light compartment (DL) and percentage of time spent in center (OF) as indicating anxiety-like behavior and the parameters sum of entries into open and closed arms (EPM), and path length (OF) as indicating exploratory activity. The parameter number of entries into light compartment (DL) is regarded as indicating both anxiety-like behavior and exploratory activity.

\section{Elevated plus maze test}

At age of $50 \pm 1$ days the offspring were tested in the EPM (Lister, 1990; Hogg, 1996; Holmes, 2001). The plus shaped apparatus was elevated $50 \mathrm{~cm}$ above the ground and illuminated by an overhead bulb (23 lux). The relatively low illumination level in this and the following tests was chosen in order to decrease the overall averseness of the testing situation. The maze consisted of two opposing open arms and two opposing arms enclosed with $20 \mathrm{~cm}$ high walls, all four extending from a central platform. The platform measured $5 \mathrm{~cm} \times 5 \mathrm{~cm}$, whereas the arms were each $30 \mathrm{~cm}$ long and $5 \mathrm{~cm}$ wide. After spending $1 \mathrm{~min}$ in an empty cage, each mouse was placed on the central platform of the EPM and was allowed to freely explore the apparatus for $5 \mathrm{~min}$. The movements of the animals were recorded by a camera and analyzed by use of the computer programs Optimas 6.5N (Media Cybernetics) and Tracking Analysis 1.1.1 (Lars Lewejohann ${ }^{1}$ ). The parameters measured by Tracking Analysis were the sum of entries into open and closed

${ }^{1}$ http://www.phenotyping.com arms, the percentage of time spent on open arms and the percentage of entries into open arms.

\section{Dark light test}

The offspring was tested in the DL (Crawley and Goodwin, 1980; Holmes, 2001) at age of $54 \pm 2$ days. The DL test apparatus consisted of a modified Macrolon cage type III, which was divided into two parts by a PVC plate. The first part, designated as the dark compartment, comprised one third of the cage, was painted black and could be covered with a dark lid. The second part, the light compartment, consisted of two thirds of the cage, had transparent walls and was illuminated by a bulb hanging above the apparatus (13 lux). The two compartments were connected via a small sliding door inserted in the PVC plate. Each mouse was placed inside the dark compartment with lid and sliding door closed. The individual remained there for $1 \mathrm{~min}$ before the sliding door was opened and the mouse could freely explore the DL apparatus for $5 \mathrm{~min}$. The parameters analyzed for each animal were the latency to enter the light compartment, the number of entries into the light compartment and the percentage of time spent in the dark compartment.

\section{Open field test}

At age of $59 \pm 3$ days the offspring were tested for their anxietylike and exploratory behavior in the OF (Treit and Fundytus, 1988; Holmes, 2001). The OF test apparatus was a white $80 \mathrm{~cm} \times 80 \mathrm{~cm}$ box with walls $42 \mathrm{~cm}$ high that was illuminated by an overhead bulb (13 lux). After spending $1 \mathrm{~min}$ in an empty cage, each mouse was placed in the middle of the OF arena and was allowed to freely explore it for $5 \mathrm{~min}$. The movements of the animals were recorded by camera and analyzed as described for the EPM. The parameters measured were the path length the mice traveled and the percentage of time they spent in the center of the OF (defined as the area of the OF being located at least $20 \mathrm{~cm}$ distant from the walls).

\section{STATISTICAL ANALYSIS}

Parts of the obtained data were not normally distributed and thus were transformed logarithmically. After transformation none of the data sets deviated significantly from a normal distribution, as confirmed by the One-sample Kolmogorov-Smirnov test. Univariate analysis of variance (ANOVA) was used to evaluate differences between more than two independent samples. More than two dependent samples were compared using a Repeated Measures ANOVA. In case of significant variation proven by the ANOVA, pairwise comparisons between independent samples were performed using Independent Samples $t$-tests (two-tailed). Dependent samples were compared by means of Paired Samples $t$-tests. In case of multiple comparisons sequential Bonferroni correction was applied (Rice, 1989). $P$ values given in the text are original $P$ values as obtained from the $t$-tests since all $P$ values did remain significant following sequential Bonferroni correction. For the pairwise comparisons the data of males and females were pooled in the parameters that did not differ between the sexes according to the ANOVA. Statistical significance was set at $P<0.05$. All tests were calculated using the software package SPSS (SPSS for Windows, Release 11.5.0., 2002). 


\section{RESULTS}

\section{EFFECTS OF TREATMENT ON BEHAVIOR OF THE MOTHERS}

Mothers were either treated with UMB during pregnancy and lactation, or they received a control treatment with NB. The latency to enter the treatment quarter did neither differ between the two treatment conditions [ANOVA; $F(1,17)=0.160, P=0.694$ ], nor between the first and the fifth treatment [ANOVA; $F(1,17)=2.366$, $P=0.142]$. However, two-way ANOVA revealed a significant main effect of type of treatment $[F(1,17)=19.212, P<0.0001]$ and time of treatment $[F(1,17)=4.657, P=0.046]$ on the mothers' percentage of time spent in the treatment quarter (Figure 1). UMB mothers spent significantly more time in the treatment quarter than

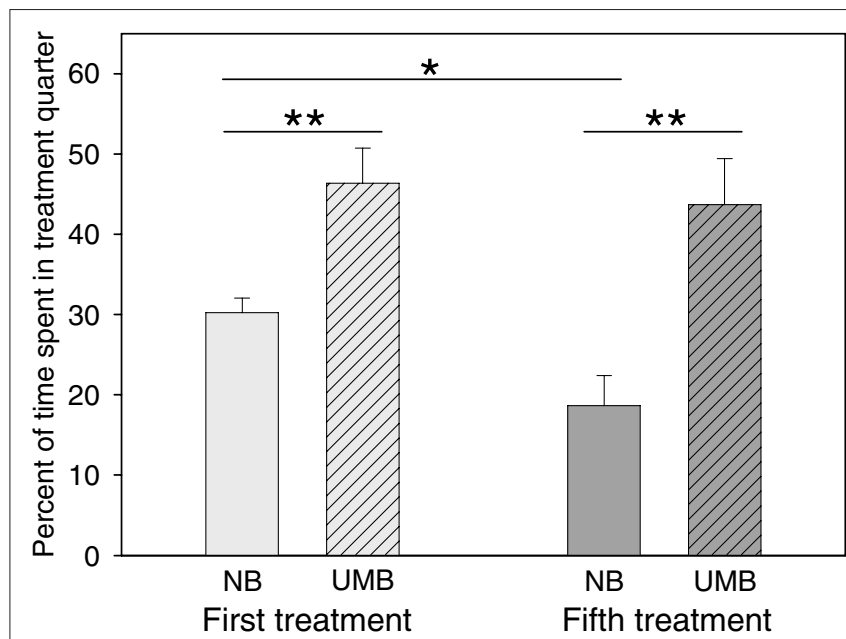

FIGURE 1 |Time spent in treatment quarter. NB, neutral bedding; UMB, unfamiliar male bedding. Data are shown as mean + SEM. Statistics: repeated measures ANOVA; there was a significant main effect of treatment $(P<0.0001)$ and time of treatment $(P=0.046)$; post hoc testing: Bonferroni corrected paired samples t-tests: ${ }^{*} P<0.01,{ }^{*} P<0.05$. Data were obtained from 10 NB mothers and 9 UMB mothers. control mothers during the first ( $t$-test; $t=-3.530, P=0.003)$ as well as during the fifth treatment $(t=-3.735, P=0.002)$. Whereas the percent of time spent in treatment quarter of UMB mothers did not differ between the first and the fifth treatment (paired-samples $t$-test; $t=0.496, P=0.634), \mathrm{NB}$ mothers spent significantly less time in the treatment quarter during the fifth than during the first treatment $(t=2.922, P=0.017)$.

\section{EFFECTS OF TREATMENT ON LITTER SIZE AND SEX RATIO}

Litters of the two treatment conditions did not differ significantly concerning litter size (UMB: $7 \pm 0.5$, NB: $6.5 \pm 0.3 ; t=-0.872$, $P=0.396$ ) or sex ratio (UMB: $56.8 \pm 7.2 \%$ males, NB: $55.7 \pm 6.4 \%$ males; $t=0.011, P=0.991)$.

\section{EFFECTS OF TREATMENT AND GENOTYPE ON OFFSPRING ANXIETY-LIKE BEHAVIOR AND EXPLORATION Elevated plus maze test}

Concerning the sum of entries into open and closed arms ANOVA detected a significant main effect of genotype $[F(2,105)=12.779$, $P<0.0001$; Figure 2A; Table 1]. Pairwise comparisons indicated that 5-HTT $-/-$ mice entered fewer arms than 5-HTT +/- (NB: $t=2.742, P=0.009$; UMB: $t=2.900, P=0.006)$ and wildtype mice (NB: $t=3.123, P=0.005$; UMB: $t=3.077, P=0.005$; Table 3). There were no significant main effects of gender and treatment.

The parameter percentage of time spent on open arms (Figure 2B) was not significantly influenced by gender, treatment or genotype. Similarly, regarding the parameter percentage of entries into open arms no main effects of gender, treatment or genotype were shown (Table 1).

Concerning all three behavioral measures no significant interactions could be found.

\section{Dark light test}

ANOVA revealed a significant main effect of genotype on the latency to enter the light compartment $[F(2,105)=4.878, P=0.009$; Figure 3A; Table 1] with homozygous individuals displaying longer

\section{$\mathbf{B}$}

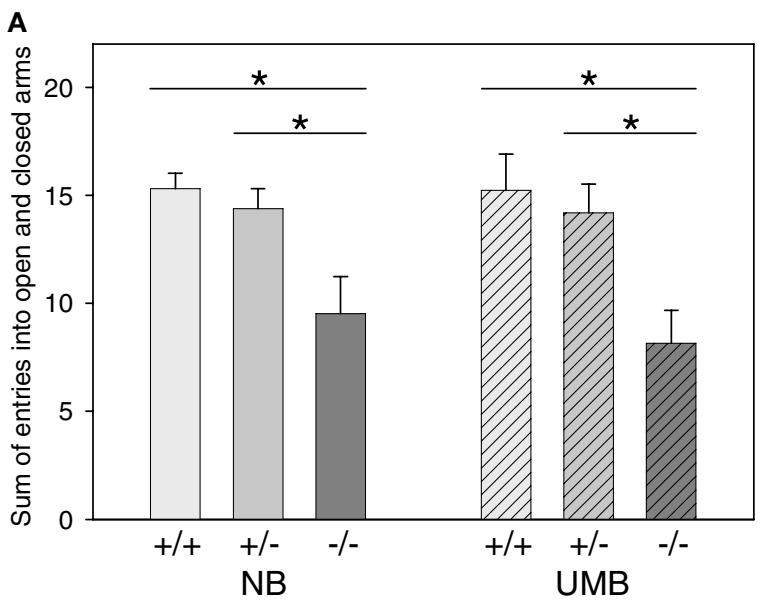

FIGURE 2 | Elevated plus maze test. NB, neutral bedding; UMB, unfamiliar male bedding; $+/+,+/,-/-$ : 5-HTT genotypes. Data are shown as mean + SEM. Statistics: ANOVA, post hoc testing: Bonferroni corrected $t$-tests: ${ }^{*} P<0.05$. Data were obtained from $36 \mathrm{NB}$ males $(6+/+, 19+/-, 11-/-$ mice), 28 NB females

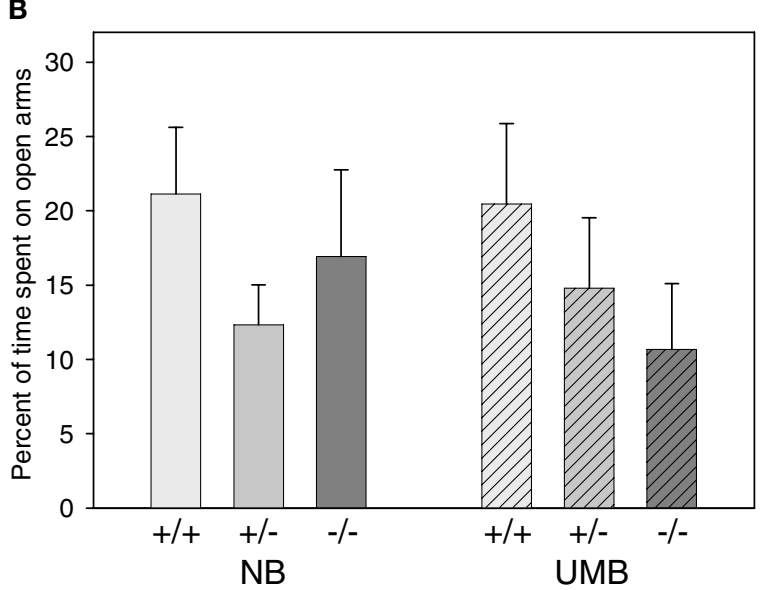

(13 +/+, $9+/-, 6-/-$ mice), 34 UMB males (10 +/+, $17+/-, 7-/-$ mice) and 19 UMB females (7+/+, $5+/-, 7-/-$ mice). (A) Sum of entries into open and closed arms. There was a significant main effect of genotype $(P<0.0001)$. (B) Percentage of time spent on open arms. There were no significant main effects. 
Table 1 | Main effects of gender, treatment and genotype.

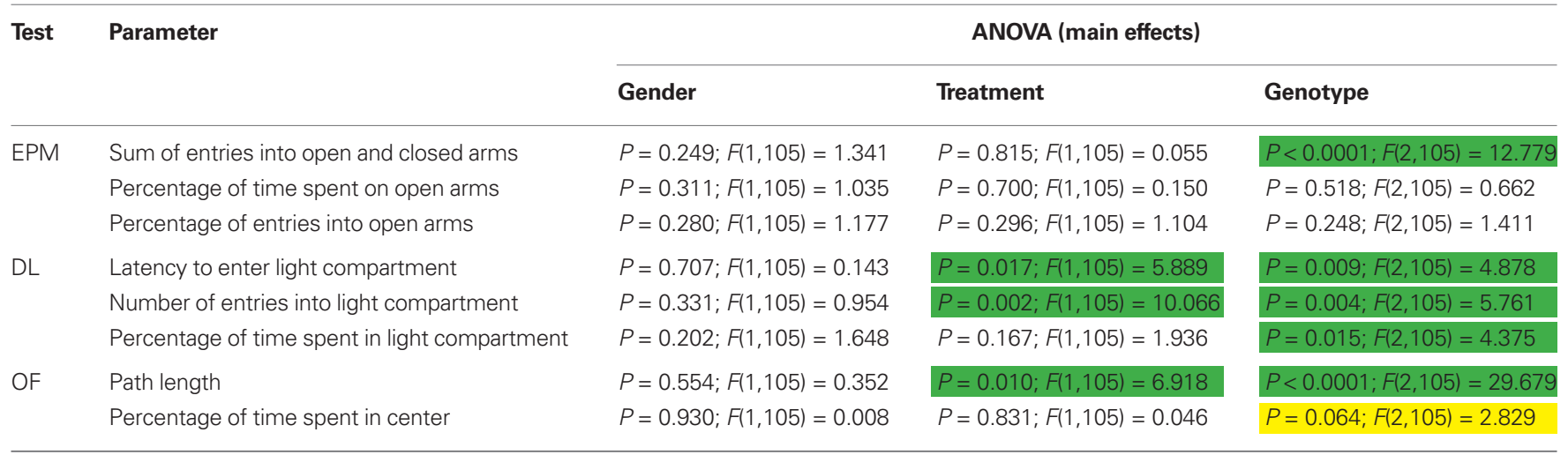

EPM, elevated plus maze test; $D L$, dark light test; OF, open field test. Statistics: ANOVA. Green: $P<0.05 ;$ yellow: $P<0.1$.
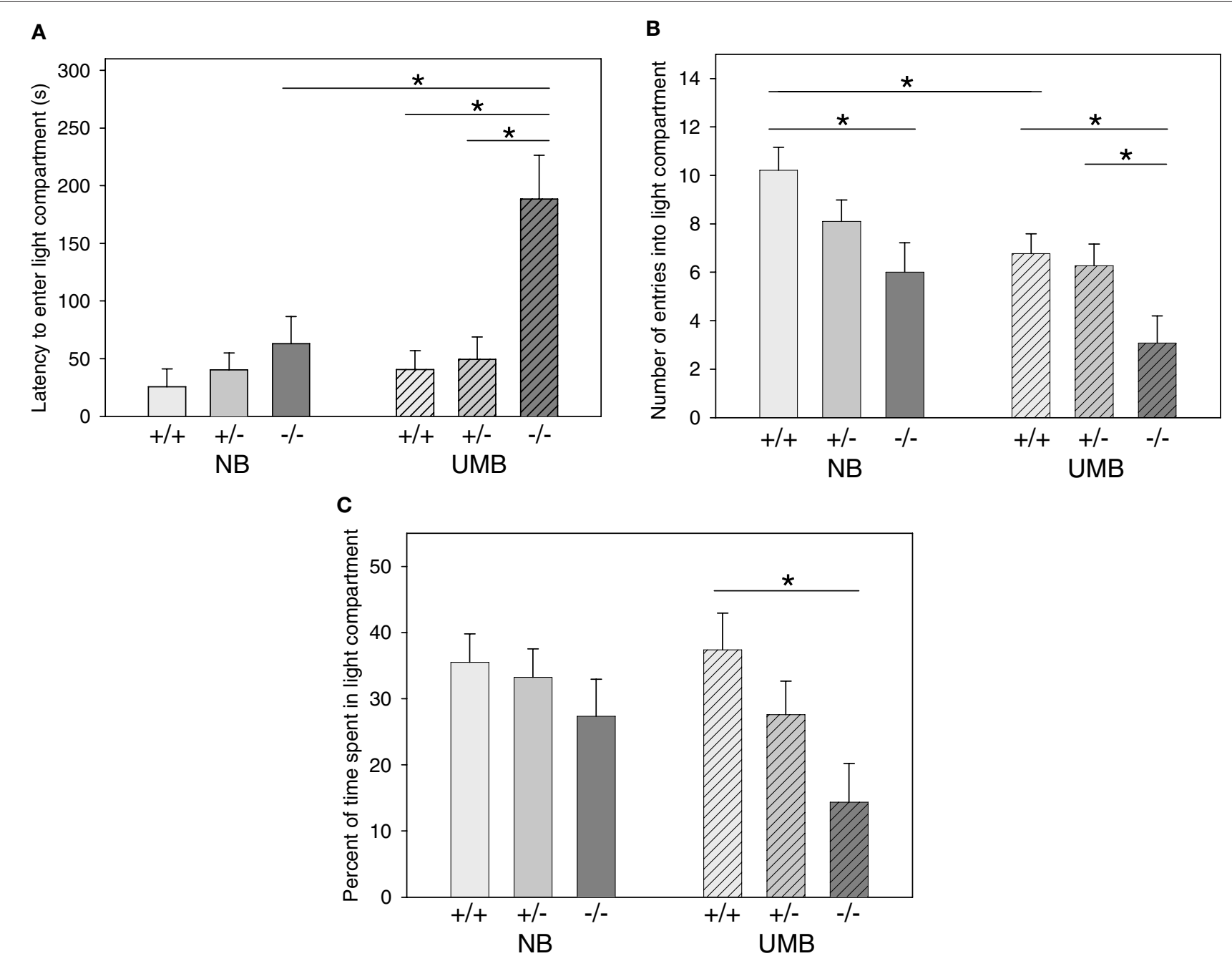

FIGURE 3 | Dark light test. NB, neutral bedding; UMB, unfamiliar male bedding; $+/+,+/-,-/-: 5-H T T$ genotypes. Data are shown as mean + SEM. Statistics: ANOVA, post hoc testing: Bonferroni corrected $t$-tests: ${ }^{*} P<0.05$. Data were obtained from $36 \mathrm{NB}$ males $(6+/+, 19+/-, 11-/-$ mice), 28 NB females $(13+/+, 9$ +/-, 6 -/- mice), 34 UMB males (10 +/+, $17+/-, 7-/-$ mice) and 19 UMB females
(7+/+, $5+/-, 7-/-$ mice). (A) Latency to enter light compartment. There was a significant main effect of genotype $(P=0.009)$ and treatment $(P=0.017)$. (B) Number of entries into light compartment. There was a significant main effect of genotype $(P=0.004)$ and treatment $(P=0.002)$. (C) Percentage of time spent in light compartment. There was a significant main effect of genotype $(P=0.015)$. 
latencies than wildtype and heterozygous animals. This effect was most distinct in UMB mice, since pairwise comparisons indicated that UMB homozygotes entered the light compartment significantly later than UMB heterozygotes $(t=-2.942, P=0.006)$ and UMB wildtypes $(t=-2.724, P=0.012)$, whereas NB homozygotes displayed a comparable latency to enter the light compartment as NB heterozygotes and wildtypes (Table 3 ). There was also a significant main effect of treatment $[F(1,105)=5.889, P=0.017]$. Particularly, homozygous UMB mice entered the light compartment distinctly later than homozygous NB animals $(t=-2.137$, $P=0.041$; Table 2). There was no significant gender effect.

Regarding the number of entries into the light compartment there was a significant main effect of genotype $[F(2,105)=5.761$, $P=0.004$; Figure 3B; Table 1] with homozygous individuals showing fewer entries than heterozygous and wildtype animals. Pairwise comparisons revealed a significant difference between homozygotes and wildtypes in both treatment conditions (UMB mice: $t=2.695, P=0.012$; NB mice: $t=2.754, P=0.009$; Table 3). There was also a difference between UMB heterozygotes and homozygotes ( $t=2.227, P=0.033)$, but NB heterozygotes did not differ from NB homozygotes. There was a significant main effect of treatment $[F(1,105)=10.066, P=0.002]$ with UMB mice entering the light compartment distinctly less frequently than NB mice. According to the pairwise comparisons UMB wildtypes displayed a significantly lower number of entries into the light compartment than control wildtypes $(t=2.696, P=0.011)$ and UMB homozygotes showed a trend to enter the light compartment less often than control homozygotes $(t=1.737, P=0.093$; Table 2$)$. Heterozygous animals did not differ significantly between the treatments. There was no significant main effect of gender.

Concerning the parameter percentage of time spent in light compartment there was a significant main effect of genotype $[F(2$, $105)=4.375, P=0.015$; Figure 3C; Table 1] with homozygotes spending least time in the light compartment. Pairwise comparisons revealed a significant difference between UMB wildtypes and homozygotes ( $t=2.859, P=0.008$; Table 3 ). There were no significant main effects of gender and treatment condition.

Concerning all three behavioral measures no significant interactions could be found.

\section{Open field test}

There was a significant main effect of genotype on the parameter path length [ANOVA; $F(2,105)=29.679, P<0.0001$; Figure 4A; Table 1] with homozygous mice covering distinctly shorter distances than both heterozygous and wildtype mice. Pairwise comparisons revealed significant differences between the genotypes for both UMB mice (wildtypes-homozygotes: $t=3.824, P=0.001$; heterozygotes-homozygotes: $t=6.586, P<0.0001$ ) and NB mice (wildtypes-homozygotes: $t=4.769, P<0.0001$; heterozygoteshomozygotes: $t=5.817, P<0.0001$; Table 3$)$. There was also a

Table 2 | Pairwise comparisons between treatment groups. Direction of significant differences see text.

\begin{tabular}{|c|c|c|c|c|}
\hline \multirow[t]{2}{*}{ Test } & \multirow[t]{2}{*}{ Parameter } & \multicolumn{3}{|c|}{ NB versus UMB } \\
\hline & & $+/+$ & $+/-$ & $-/-$ \\
\hline \multirow[t]{2}{*}{$\mathrm{DL}$} & Latency to enter light compartment & $P=0.280 ; t=-1.098$ & $P=0.946 ; t=-0.068$ & $P=0.041 ; t=-2.137$ \\
\hline & Number of entries into light compartment & $P=0.011 ; t=2.696$ & $P=0.153 ; t=1.451$ & $P=0.093 ; t=1.737$ \\
\hline OF & Path length & $P=0.123 ; t=1.580$ & $P=0.085 ; t=1.762$ & $P=0.428 ; t=0.804$ \\
\hline
\end{tabular}

$D L$, dark light test; OF, open field test; NB, neutral bedding; UMB, unfamiliar male bedding; +/+, +/-, -/-: 5-HTT genotypes. Statistics: T-test. Green: P<0.05; yellow: $P<0.1$.

Table 3 | Pairwise comparisons between genotype groups. Direction of significant differences see text.

\begin{tabular}{|c|c|c|c|c|c|c|c|}
\hline \multirow[t]{2}{*}{ Test } & \multirow[t]{2}{*}{ Parameter } & \multicolumn{2}{|c|}{ +/+ versus +/- } & \multicolumn{2}{|c|}{ +/- versus -/- } & \multicolumn{2}{|c|}{ +/+ versus -/- } \\
\hline & & NB & UMB & NB & UMB & NB & UMB \\
\hline EPM & $\begin{array}{l}\text { Sum of entries into open } \\
\text { and closed arms }\end{array}$ & $\begin{array}{l}P=0.428 \\
t=-0.799\end{array}$ & $\begin{array}{l}P=0.621 \\
t=-0.499\end{array}$ & $\begin{array}{l}P=0.009 \\
t=2.742\end{array}$ & $\begin{array}{l}P=0.006 \\
t=2.900\end{array}$ & $\begin{array}{l}P=0.005 \\
t=3.123\end{array}$ & $\begin{array}{l}P=0.005 \\
t=3.077\end{array}$ \\
\hline DL & $\begin{array}{l}\text { Latency to enter light } \\
\text { compartment }\end{array}$ & $\begin{array}{l}P=0.269 \\
t=1.119\end{array}$ & $\begin{array}{l}P=0.978 \\
t=-0.028\end{array}$ & $\begin{array}{l}P=0.429 \\
t=-0.799\end{array}$ & $\begin{array}{l}P=0.006 \\
t=-2.942\end{array}$ & $\begin{array}{l}P=0.105 \\
t=-1.672\end{array}$ & $\begin{array}{l}P=0.012 \\
t=-2.724\end{array}$ \\
\hline & $\begin{array}{l}\text { Number of entries into } \\
\text { light compartment }\end{array}$ & $\begin{array}{l}P=0.119 \\
t=-1.591\end{array}$ & $\begin{array}{l}P=0.696 \\
t=-0.394\end{array}$ & $\begin{array}{l}P=0.158 \\
t=1.438\end{array}$ & $\begin{array}{l}P=0.033 \\
t=2.227\end{array}$ & $\begin{array}{l}P=0.009 \\
t=2.754\end{array}$ & $\begin{array}{l}P=0.012 \\
t=2.695\end{array}$ \\
\hline & $\begin{array}{l}\text { Percentage of time spent } \\
\text { in light compartment }\end{array}$ & $\begin{array}{l}P=0.716 \\
t=-0.366\end{array}$ & $\begin{array}{l}P=0.202 \\
t=-1.299\end{array}$ & $\begin{array}{l}P=0.408 \\
t=0.835\end{array}$ & $\begin{array}{l}P=0.101 \\
t=1.688\end{array}$ & $\begin{array}{l}P=0.251 \\
t=1.168\end{array}$ & $\begin{array}{l}P=0.008 \\
t=2.859\end{array}$ \\
\hline OF & Path length & $\begin{array}{l}P=0.654 \\
t=0.451\end{array}$ & $\begin{array}{l}P=0.367 \\
t=0.912\end{array}$ & $\begin{array}{l}P<0.0001 \\
t=5.817\end{array}$ & $\begin{array}{l}P<0.0001 \\
t=6.586\end{array}$ & $\begin{array}{l}P<0.0001 \\
t=4.769\end{array}$ & $\begin{array}{l}P<0.001 \\
t=3.824\end{array}$ \\
\hline
\end{tabular}

EPM, elevated plus maze test; DL, dark light test; OF, open field test; NB, neutral bedding; UMB, unfamiliar male bedding; +/+, +/-, -/-: 5-HTT genotypes. Statistics: T-test. Green: $P<0.05$. 


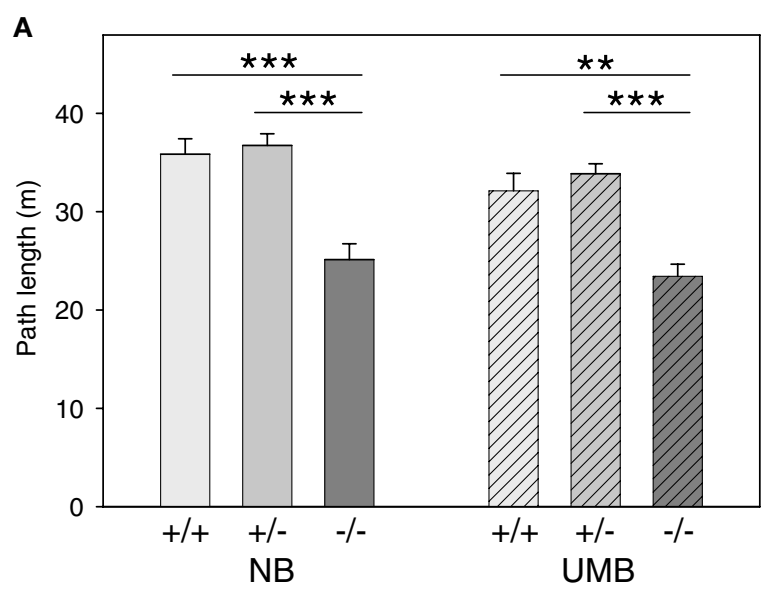

FIGURE 4 | Open field test. NB, neutral bedding; UMB, unfamiliar male bedding; +/+, +/-, -/-: 5-HTT genotypes. Data are shown as mean + SEM. Statistics: ANOVA, post hoc testing: Bonferroni corrected $t$-tests:

${ }^{*} * P<0.001,{ }^{*} P<0.01$. Data were obtained from $36 \mathrm{NB}$ males $(6+/+$

$19+/-, 11-/-$ mice), 28 NB females (13 +/+, 9 +/-, 6 -/- mice), 34 UMB males

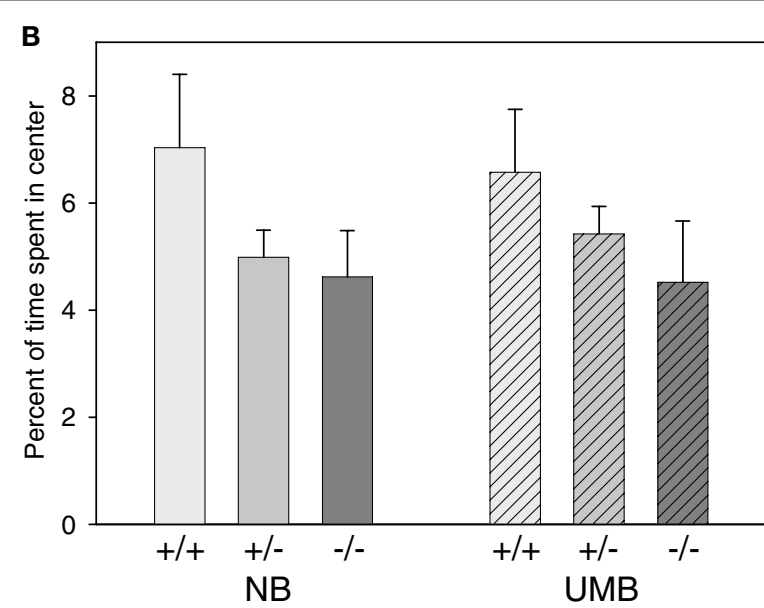

(10 +/+, $17+/-, 7-/-$ mice) and 19 UMB females ( $7+/+, 5+/-, 7-/-$ mice) . (A) Path length. There was a significant main effect of genotype $(P<0.0001)$ and treatment $(P=0.010)$. (B) Percentage of time spent in center. There were no significant main effects, but a trend towards a main effect of genotype $(P=0.064)$. significant main effect of treatment $[F(1,105)=6.918, P=0.01]$ with UMB animals covering distinctly shorter distances than control individuals. According to the pairwise comparisons particularly heterozygous NB mice showed a trend to travel larger distances than heterozygous UMB mice ( $t=1.762, P=0.085$; Table 2$)$. There was no significant main effect of gender.

Regarding the percentage of time spent in the center of the OF there was a trend towards a main effect of genotype $[F(2$, $105)=2.829, P=0.064$; Figure 4B; Table 1 ] with wildtypes spending most time in the center and homozygotes least time. There were no significant main effects of gender and treatment.

Concerning both behavioral measures no significant interactions could be found.

\section{DISCUSSION \\ EFFECTS OF TREATMENT ON BEHAVIOR OF THE MOTHERS}

Mothers were either treated with NB or UMB, which contained urine and feces of adult males. By investigating the urine of conspecifics, mice can gain information on individuality and sex of the scent mark owner both through the main and accessory olfactory systems (Hurst, 2009; Keller et al., 2009). The key information is conveyed in involatile components which are detected by direct contact with a scent source through the vomeronasal system; a procedure that is generally thought necessary to elicit the Bruce effect (see Introduction; Brennan, 2009; Hurst, 2009). Thus, it is not surprising that $\mathrm{NB}$ and $\mathrm{UMB}$ females did not differ concerning their latencies to enter the treatment quarter. Interestingly, both during the first and fifth treatment UMB females stayed in the treatment quarters longer than NB females, suggesting that the odor cues left by adult males prolonged the time the pregnant females spent exploring this quarter of the cage. Providing information about the males' physiological state and infanticidal potential (Mandillo and D'Amato, 1997), the odor cues contained in UMB were highly relevant for the females. Consistently, the time UMB females spent in the treatment quarter did not differ between the first and the fifth treatment, whereas NB females habituated to the treatment procedure. Taken together, these findings indicate that the UMB dams were aware of the relevance of the odor cues, which simulated the presence of potentially infanticidal males and the resulting risk of infant killing. Hence, it can be assumed that a threatening environment was created.

\section{EFFECTS OF TREATMENT ON OFFSPRING ANXIETY-LIKE BEHAVIOR AND EXPLORATION}

In summary, the appliance of our newly developed paradigm had a profound effect on the offspring behavioral profile in adulthood: The treatment with UMB during pre- and early postnatal life increased levels of anxiety-like behavior in the DL test (latency to enter light compartment/number of entries into light compartment) and decreased measures of exploratory activity (number of entries into light compartment/path length) in the OF test and DL, as indicated by the main effects of the ANOVA. Paired comparisons of the specific subgroups could not always locate the treatment effects to one specific genotype group. Only UMB wildtypes were found to enter the light compartment of the DL less often than NB wildtypes and UMB 5-HTT -/- individuals entered the light compartment later than NB 5-HTT -/- individuals. The main effects of treatment on the other parameters seem to be caused by slightly increased anxiety-related behavior and decreased exploratory locomotion in mice of all three genotypes, rather than by pronounced differences between the treatment groups in mice of a specific genotype. Admittedly, the main effects of treatment could not be found in all parameters, especially not in the EPM test. This could be due to the low illumination level applied in the EPM, since the behavior in the EPM seems to be strongly dependant upon lighting conditions (Clément et al., 2002).

There have been earlier attempts to apply olfactory cues in early phases of life in order to shape offspring behavioral profile. But as far as we know, we are the first to achieve increased anxiety-like behavior and reduced exploratory locomotion in the offspring by 
confronting mothers with odor cues. For example, Moles et al. placed dams in cages containing male soiled bedding for $15 \mathrm{~min}$ daily during the first 2 weeks of lactation, resulting in decreased anxiety-like behavior in the male offspring (Moles et al., 2004, 2008). However, the same effect was found when mothers were instead placed in cages containing clean bedding (Moles et al., 2008), indicating that the reduced anxiety-like behavior of the sons was probably due to an unspecific handling effect. Coutellier et al. applied an apparatus consisting of a nest cage and a foraging cage (Coutellier et al., 2008). However, the simulated threat of predation, indicated by rat odor in the foraging cage, failed to exert a main effect on the anxiety-related behavior of the offspring.

Other attempts have been made to modify adult behavior by modeling an adverse environment during early phases of life. During the prenatal phase pregnant females were exposed to stressors such as daily handling, repeated saline injections, light and/or noise, forced swimming and repeated restraint (Archer and Blackman, 1971; Vallée et al., 1997; Ward et al., 2000; Kofman, 2002; Maccari et al., 2003; Chung et al., 2005; Richardson et al., 2006; Weinstock, 2008). In rats these paradigms mostly caused increased anxiety-like behavior and decreased locomotion in the young, whereas in mice the treatment does not seem to affect the offspring in a consistent way. In other studies adverse experience during the early postnatal phase was created by exposing the offspring to low maternal care (Caldji et al., 1998; Carola et al., 2006, 2008) or by experimentally inducing maternal separation (MS) (Huot et al., 2001; Pryce and Feldon, 2003; Romeo et al., 2003; Millstein and Holmes, 2007; Parfitt et al., 2007; Veenema et al., 2007). Whereas increased anxiety-like behavior can often, but not always, be shown in MS treated animals, low maternal care reliably leads to enhanced anxiety-like behavior in the offspring. In summary, adverse early life experience often increases offspring anxiety-like behavior and decreases exploratory locomotion. The effects of a dangerous environment during pre- and early postnatal life in this study confirm this general finding.

Compared to most stressors applied to induce adverse experiences, the confrontation with olfactory cues of unfamiliar males appears to be a rather mild intervention; although confirmation from stress hormone analysis is not yet at hand. Thus, at first sight, it seems surprising that this procedure is capable of permanently affecting offspring behavioral profile. Presumably, the newly developed paradigm owes its notable influence on offspring behavior to its strong ecological relevance: In accordance with current evolutionary theory the effects of early life environmental stimuli on behavioral traits can represent adaptive maternal effects (Mousseau and Fox, 1998; Qvarnström and Price, 2001; Dufty et al., 2002; Kaiser and Sachser, 2005, 2009), that is, mothers try to maximize their own Darwinian fitness by adjusting their offspring efficiently to the current or future environmental conditions. The confrontation with bedding material from several male individuals of different strains, alternating every treatment, simulates an environment populated by a high number of potentially infanticidal males, and thus a threatening environment for a female and her young (see Introduction). When living in a dangerous habitat, it is highly adaptive for a mouse to behave careful and unobtrusively. Thus, it would be advantageous for mothers in such an environment to program their offspring to exhibit high anxiety-like and low exploratory behavior. Therefore, the behavioral alterations measured in $\mathrm{UMB}$ offspring could indeed represent adaptive effects. It should be noted, however, that this conclusion is so far supported only as a proof-of-principle with the 5-HTT knockout mouse model in this study.

Whether these modulations of offspring behavioral profile are mediated by intra-uterine mechanisms during gestation (e.g., Kaiser and Sachser, 2005), by physiological or behavioral maternal factors during lactation (e.g., Meaney, 2001) or by direct experience of the pups during the pre-weaning period remains to be examined. In order to decipher possible mechanisms, in an ongoing study we currently investigate whether the simulation of a threatening environment takes effect during the prenatal, postnatal, or both phases. In this context we are also studying the corticosterone stress response of mothers to the different olfactory treatments as a potential mediator of the observed treatment effects. Since maternal care has been suggested to be an important mediator of the effects of environmental adversity on neural development in the offspring (Meaney, 2001), it might also be interesting to evaluate the maternal behavior of the dams under different treatment conditions.

\section{EFFECTS OF GENOTYPE AND GENOTYPE $\times$ TREATMENT INTERACTIONS ON OFFSPRING ANXIETY-LIKE BEHAVIOR AND EXPLORATION}

As a general finding, homozygous 5-HTT knockout mice showed increased measures of anxiety-like behavior [latency to enter light compartment/number of entries into light compartment/percentage of time spent in light compartment/percentage of time spent in center (trend)] in the DL and OF as well as decreased locomotory activity in the EPM, DL and OF (sum of entries into open and closed arms/number of entries into light compartment/path length) as compared to heterozygous and wildtype animals.

This result confirms earlier findings in 5-HTT -/- mice (Holmes et al., 2003b,c; Lesch, 2005; Zhao et al., 2006; Kalueff et al., 2007). In contrast to previous studies, the differences in anxiety-like behavior did not prove to be significant in the EPM. This is, however, most likely due to methodological differences in testing procedures. For instance the applied test apparatuses and illumination level differed clearly between the named studies, the latter ranging in the EPM between 200 lux (Holmes et al., 2003c) and 13 lux in this study. Generally, it is known that results of behavioral tests can differ between laboratories, even when the same testing procedures are used (Crabbe et al., 1999; Clément et al., 2002; Lewejohann et al., 2006).

Although no significant interaction between treatment and genotype could be found, there was some indication that the behavioral differences between 5 -HTT $-/-,+/-$ and wildtype mice were intensified when they experienced adverse early life circumstances: In the DL homozygous 5-HTT knockout mice of the UMB condition entered the light compartment significantly later than UMB wildtypes and heterozygotes, whereas NB 5-HTT -/- mice did not behave differently from NB wildtypes and heterozygotes (see Figure 3A). A similar pattern could be seen concerning the percentage of time spent in the light compartment of the DL (see Figure 3C). Furthermore, pairwise comparisons revealed that the increased anxiety-related behavior of 5 -HTT $-/-$ mice in the DL was most pronounced in UMB mice, indicating that the genetically induced behavioral alterations in 5-HTT -/- mice were enhanced 
by an adverse early environment. Consistently, genetic inactivation of the 5-HTT in mice leads to increased vulnerability to the anxiogenic effects of predator stress (i.e., cat odor) (Adamec et al., 2006). Similarly, the experience of low maternal care led to increased anxiety and depression-related behavior in heterozygous 5-HTT knockout mice (Carola et al., 2008). Thus, changes in emotionality following exposure to adverse circumstances seem to be moderated by 5 -HTT genotype.

The mechanisms underlying this phenomenon are not yet fully understood. Presumably the 5-HTT genotype influences the individual's sensitivity to mild stressors and pathogenic effects of the environment (Kendler et al., 2005; Mandelli et al., 2007). Consistently, 5-HTT knockout mice display exaggerated pituitary and adreno-medullary responses to stressors (Li et al., 1999; Murphy et al., 2001; Tjurmina et al., 2002). Electrical patterns of neural activity in the PFC-amygdala pathway are related to the retrieval and expression of conditioned fear (Seidenbecher et al., 2003). Interestingly, in experiments with Pavlovian fear conditioning 5-HTT -/- mice exhibit a significant deficit in fear extinction recall, that is, the long-term extinction of negative experience proceeds in a significantly slower way than in wildtypes (Wellman et al., 2007). Furthermore, 5-HTT knockout mice show anatomical abnormalities in the prefrontal cortex (Wellman et al., 2007). Concerning the molecular level, Carola et al. (2008) show selectively elevated levels of BDNF mRNA in the hippocampus of 5-HTT -/- mice exposed to low maternal care. They argue that 5-HT plays a similar role in modifying the long-term behavioral effects of rearing environment in diverse mammalian species and identify BDNF as a molecular substrate of this risk factor. In accordance with the findings in mice, in humans 5-HTT-genotype related alterations in stress reactivity (Gotlib et al., 2008) as well as possibly inadequate regulation and integration of amygdala-mediated arousal (Pezawas et al., 2005) apparently increase the susceptibility to emotional disorders in the context of accumulating environmental adversity (Pezawas et al., 2005; Canli et al., 2006; Canli and Lesch, 2007; Gotlib et al., 2008). The short 5-HTT allele has been associated with increased startle responses (Brocke et al., 2006) and greater activation in limbic and cortical brain regions in response to emotionally relevant stimuli (Dannlowski et al., 2007; Canli et al., 2008; Munafò et al., 2008).

\section{REFERENCES}

Adamec, R., Burton, P., Blundell, J., Murphy, D. L., and Holmes, A. (2006). Vulnerability to mild predator stress in serotonin transporter knockout mice. Behav. Brain Res. 170, 126-140.

Allen, E. (1922). The oestrous cycle in the mouse. Am. J. Anat. 30, 297.

Archer, J. E., and Blackman, D. E. (1971). Prenatal psychological stress and offspring behavior in rats and mice. Dev. Psychobiol. 4, 193-248.

Belzung, C., and Griebel, G. (2001). Measuring normal and pathological anxiety-like behaviour in mice: a review. Behav. Brain Res. 125, 141-149.

Bengel, D., Murphy, D. L., Andrews, A. M., Wichems, C. H., Feltner, D., Heils, A., Mössner, R., Westphal, H., and
Lesch, K.-P. (1998). Altered brain serotonin homeostasis and locomotor insensitivity to 3,4-methylenedioxymethamphetamine ("ecstasy") in serotonin transporter-deficient mice. Mol. Pharmacol. 53, 649-655.

Brennan, P. A. (2009). Outstanding issues surrounding vomeronasal mechanisms of pregnancy block and individual recognition in mice. Behav. Brain Res. 200, 287-294.

Brocke, B., Armbruster, D., Müller, J., Hensch, T., Jacob, C. P., Lesch, K.-P., Kirschbaum, C., and Strobel,A. (2006). Serotonin transporter gene variation impacts innate fear processing: acoustic startle response and emotional startle. Mol. Psychiatry 11, 1106-1112.

Brown, J., Cohen, P., Johnson, J. G., and Smailes, E. M. (1999). Childhood

The profile of humans with two copies of the short 5-HTT allele is closely modeled by the $50 \%$ reduction of 5 -HTT expression in 5-HTT +/- mice (Bengel et al., 1998; Holmes et al., 2003b). Despite their diminished 5-HTT expression, heterozygous 5-HTT knockout animals usually behave similar to wildtype mice (Holmes et al., 2003c; Lesch et al., 2003). Accordingly, 5-HTT +/-mice in this study did not exhibit pronounced behavioral differences from wildtype mice. Consistently, they were neither influenced by an early adverse environment in the same way as the homozygotes, but displayed the same behavioral phenotypes as the wildtype controls. It was assumed that the serotonergic dysfunction in 5-HTT +/- mice may only cause measurable behavioral abnormalities under challenging environmental conditions (Holmes et al., 2003c; Lesch, 2005). Maybe, the degree of adverseness of the environmental circumstances in our study was too low, allowing heterozygous 5-HTT knockout mice to compensate for their genetic deficiency and to successfully cope with the situation. Possibly, more challenging treatment conditions, for instance direct contact between the mothers and unfamiliar males, would cause stronger behavioral effects in the heterozygotes. Alternatively, potentially present subtle behavioral differences could be made noticeable using different testing procedures.

\section{CONCLUSIONS}

By applying a new ecologically relevant paradigm we conclude: If 5 -HTT $+/-$ mothers live in a dangerous world during pregnancy and lactation, their offspring behavioral phenotype will, in principle, be shaped in an adaptive way. The decreased exploratory locomotion and increased anxiety-like behavior represent alterations preparing the young for an adverse environment. This process is, however, modulated by 5 -HTT genotype, bearing the risk that individuals with impaired serotonergic neurotransmission (5-HTT $-/-)$ will develop an exaggerated, potentially pathological level of anxiety from gene $\times$ environment interactions.

\section{ACKNOWLEDGMENTS}

This study was supplied by a grant from the German Science Foundation (DFG) to N. Sachser, A. Schmitt, and K. P. Lesch (SFB/ TRR58, Project A1 and A5).

abuse and neglect: specificity of effects on adolescent and young adult depression and suicidality. J. Am. Acad. Child Adolesc. Psychiatry 38, 1490-1496.

Bruce, H. M. (1959). An exteroceptive block to pregnancy in the mouse. Nature 184, 105.

Bruce, H.M. (1960). A block to pregnancy in the mouse caused by proximity of strange males. J. Reprod. Fertil. 1, 96.

Caldji, C., Tannenbaum, B., Sharma, S., Francis, D., Plotsky, P. M., and Meaney, M. J. (1998). Maternal care during infancy regulates the development of neural systems mediating the expression of fearfulness in the rat. Proc. Natl. Acad. Sci. U.S.A. 95 5335-5340.

Canli, T., Congdon, E., Todd Constable, R., and Lesch, K. P. (2008). Additive effects of serotonin transporter and tryptophan hydroxylase-2 gene variation on neural correlates of affective processing. Biol. Psychol. 79, 118-125.

Canli, T., and Lesch, K.-P. (2007). Long story short: the serotonin transporter in emotion regulation and social cognition. Nat. Neurosci. 10, 1103-1109.

Canli, T., Qiu, M., Omura, K., Congdon, E., Haas, B. W., Amin, Z., Herrmann, M. J., Constable, R. T., and Lesch, K. P. (2006). Neural correlates of epigenesis. Proc. Natl. Acad. Sci. U.S.A. 103, 16033-16038.

Carola, V., Frazzetto, G., and Gross, C. (2006). Identifying interactions between genes and early environment in the mouse. Genes Brain Behav. 5, 189-199. 
Carola, V., Frazzetto, G., Pascucci, T., Audero, E., Puglisi-Allegra, S., Cabib, S., Lesch, K. P., and Gross, C. (2008). Identifying molecular substrates in a mouse model of the serotonin transporter $\times$ environment risk factor for anxiety and depression. Biol. Psychiatry 63, 840-846.

Carroll, J. C., Boyce-Rustay, J. M., Millstein, R., Yang, R., Wiedholz, L. M., Murphy, D. L., and Holmes, A. (2007). Effects of mild early life stress on abnormal emotion-related behaviors in 5-HTT knockout mice. Behav. Genet. 37, 214-222.

Caspi, A., Sugden, K., Moffitt, T. E., Taylor, A., Craig, I. W., Harrington, H., McClay, J., Mill, J., Martin, J., Braithwaite,A., and Poulton, R. (2003). Influence of life stress on depression: moderation by a polymorphism in the 5-HTT gene. Science 301, 386-389.

Champagne, F.A., and Curley, J. P. (2005). How social experiences influence the brain. Curr. Opin. Neurobiol. 15, 704-709.

Chung, H. J., Reyes, A. B. V., Watanabe, K., Tomogane, H., and Wakasugi, N. (1997). Embryonic abnormality caused by male pheromonal effect in pregnancy block in mice. Biol. Reprod. 57, 312-319.

Chung, S., Son, G. H., Park, S. H., Park, E., Lee, K. H., Geum, D., and Kim, K. (2005). Differential adaptive responses to chronic stress of maternally stressed male mice offspring. Endocrinology 146, 3202-3210.

Clément, Y., Calatayud, F., and Belzung, C. (2002). Genetic basis of anxiety-like behaviour: a critical review. Brain Res. Bull. 57, 57-71.

Coutellier, L., Friedrich, A.-C., Failing, K., Marashi, V., and Würbel, H. (2008). Effects of rat odour and shelter on maternal behaviour in C57BL/6 dams and on fear and stress responses in their adult offspring. Physiol. Behav. 94, 393-404.

Crabbe, J. C., Wahlsten, D., and Dudek, B.C. (1999). Genetics of mouse behavior: interactions with laboratory environment. Science 284, 1670-1672.

Crawley, J., and Goodwin, F. K. (1980). Preliminary report of a simple animal behavior model for the anxiolytic effects of benzodiazepines. Pharmacol. Biochem. Behav. 13, 167-170.

Dannlowski, U., Ohrmann, P., Bauer, J., Kugel, H., Baune, B. T., Hohoff, C., Kersting, A., Arolt, V., Heindel, W., Deckert, J., and Suslow, T. (2007). Serotonergic genes modulate amygdala activity in major depression. Genes Brain Behav. 6, 672-676.

deCatanzaro, D., Beaton, E. A., Khan, A., and Vella, E. (2006). Urinary oestradiol and testosterone levels from novel male mice approach values sufficient to disrupt early pregnancy in nearby inseminated females. Reproduction 132, 309-317.

deCatanzaro, D., Zacharias, R., and Muir, C. (1996). Disruption of early pregnancy by direct and indirect exposure to novel males in mice: comparison of influences of preputialectomized and intact males. J. Reprod. Fertil. 106, 269-274.

Dufty, A. R., Clobert, J., and Møller, A. P. (2002). Hormones, developmental plasticity and adaptation. Trends Ecol. Evol. 17, 190.

Elwood, R. W., and Kennedy, H. F. (1991). Selectivity in paternal and infanticidal responses by male mice: effects of relatedness, location, and previous sexual partners. Behav. Neural Biol. 56, 129-147.

Gotlib, I. H., Joormann, J., Minor, K. L., and Hallmayer, J. (2008). HPA axis reactivity: a mechanism underlying the associations among 5-HTTLPR, stress, and depression. Biol Psychiatry 63, 847-851.

Gross, C., and Hen, R. (2004). The developmental origins of anxiety. Nat. Rev. Neurosci. 5, 545-552.

Heim, C., and Nemeroff, C. B. (2001). The role of childhood trauma in the neurobiology of mood and anxiety disorders: preclinical and clinical studies. Biol. Psychiatry 49, 1023-1039.

Hogg, S. (1996). A review of the validity and variability of the elevated plusmaze as an animal model of anxiety. Pharmacol. Biochem. Behav. 54, 21-30.

Holmes,A. (2001). Targeted genemutation approaches to the study of anxiety-like behavior in mice. Neurosci. Biobehav. Rev. 25, 261-273.

Holmes, A., Li, Q., Murphy, D. L., Gold, E., and Crawley, J. N. (2003a). Abnormal anxiety-related behavior in serotonin transporter null mutant mice: the influence of genetic background. Genes Brain Behav. 2, 365-380.

Holmes, A., Murphy, D. L., and Crawley, J. N. (2003b). Abnormal behavioral phenotypes of serotonin transporter knockout mice: parallels with human anxiety and depression. Biol. Psychiatry 54, 953-959.

Holmes, A., Yang, R. J., Lesch, K.-P., Crawley, J. N., and Murphy, D. L. $(2003 c)$. Mice lacking the serotonin transporter exhibit 5-HT(1A) receptor-mediated abnormalities in tests for anxiety-like behavior. Neuropsychopharmacology 28, 2077-2088.

Huot, R. L., Thrivikraman, K. V., Meaney, M. J., and Plotsky, P. M. (2001). Development of adult ethanol preference and anxiety as a consequence of neonatal maternal separation in long evans rats and reversal with antidepressant treatment. Psychopharmacology (Berl.) 158, 366-373.

Hurst, J.L. (2009). Female recognition and assessment of males through scent. Behav. Brain Res. 200, 295-303.

Kaiser, S., and Sachser, N. (2005). The effects of prenatal social stress on behaviour: mechanisms and function. Neurosci. Biobehav. Rev. 29, 283-294.

Kaiser, S., and Sachser, N. (2009). Effects of prenatal social stress on offspring development: pathology or adaptation? Curr. Dir. Psychol. Sci. 18, 118.

Kalueff, A. V., Fox, M. A., Gallagher, P. S. and Murphy, D. L. (2007). Hypolocomotion, anxiety and serotonin syndrome-like behavior contribute to the complex phenotype of serotonin transporter knockout mice. Genes Brain Behav. 6, 389-400.

Keller, M., Baum, M. J., Brock, O., Brennan, P. A., and Bakker, J. (2009). The main and the accessory olfactory systems interact in the control of mate recognition and sexual behavior. Behav. Brain Res. 200, 268-276.

Kendler, K. S., Kuhn, J. W., Vittum, J., Prescott, C. A., and Riley, B. (2005). The interaction of stressful life events and a serotonin transporter polymorphism in the prediction of episodes of major depression: a replication. Arch. Gen. Psychiatry 62, 529-535.

Kofman, O. (2002). The role of prenatal stress in the etiology of developmental behavioural disorders. Neurosci. Biobehav. Rev. 26, 457-470.

Lesch, K. P. (2004). Gene-environment interaction and the genetics of depression. J. Psychiatry Neurosci. 29, 174-184.

Lesch, K. P. (2005). Genetic alterations of the murine serotonergic gene pathway: the neurodevelopmental basis of anxiety. In Handbook of Experimental Pharmacology, Vol. 169, F. Holsboer and A. Ströhle, eds (Berlin, Springer), pp. 71-112.

Lesch, K.-P., Bengel, D., Heils, A., Sabol, S.Z., Greenberg, B. D., Petri, S., Benjamin, J., Müller, C. R., Hamer, D. H., and Murphy, D. L. (1996). Association of anxiety-related traits with a polymorphism in the serotonin transporter gene regulatory region. Science 274, 1527-1531.

Lesch, K. P., and Gutknecht, L. (2005). Pharmacogenetics of the serotonin transporter. Prog. Neuropsychopharmacol.Biol.Psychiatry 29, 1062-1073.

Lesch, K. P., and Merschdorf, U. (2000). Impulsivity, aggression, and serotonin: a molecular psychobiological perspective. Behav. Sci. Law 18, 581-604.

Lesch, K. P., Zeng, Y., Reif, A., and Gutknecht, L. (2003). Anxiety-related traits in mice with modified genes of the serotonergic pathway. Eur. J. Pharmacol. 480, 185-204.

Lewejohann, L., Reinhard, C., Schrewe, A., Brandewiede, J., Haemisch, A., Görtz, N., Schachner, M., and Sachser, N. (2006). Environmental bias? Effects of housing conditions, laboratory environment and experimenter on behavioral tests. Genes Brain Behav. 5, 64-72.

Li, Q., Wichems, C., Heils, A., Van De Kar, L. D., Lesch, K.-P., and Murphy, D. L. (1999). Reduction of 5-hydroxytryptamine (5-HT)(1A)mediated temperature and neuroendocrine responses and 5-HT(1A) binding sites in 5-HT transporter knockout mice. J. Pharmacol. Exp. Ther. 291, 999-1007.

Lister, R. G. (1990). Ethologically-based animal models of anxiety disorders. Pharmacol. Ther. 46, 321-340.

Maccari, S., Darnaudery, M., MorleyFletcher, S., Zuena, A. R., Cinque, C. and Van Reeth, O. (2003). Prenatal stress and long-term consequences: implications of glucocorticoid hormones. Neurosci. Biobehav. Rev. 27, 119-127.

Mandelli, L., Serretti, A., Marino, E. Pirovano, A., Calati, R., and Colombo, C. (2007). Interaction between serotonin transporter gene, catechol-O-methyltransferase gene and stressful life events in mood disorders. Int. J. Neuropsychopharmacol. 10, 437-447.

Mandillo, S., and D'Amato, F. R. (1997). Effect of strange male odour on parental care in lactating female mice. Anim. Behav. 54, 901-910.

Meaney, M. J. (2001). Maternal care, gene expression, and the transmission of individual differences in stress reactivity across generations. Annu. Rev. Neurosci. 24, 1161-1192.

Millstein, R. A., and Holmes, A. (2007). Effects of repeated maternal separation on anxiety- and depression-related phenotypes in different mouse strains. Neurosci. Biobehav. Rev. 31, 3-17.

Moles, A., Rizzi, R., and D'Amato, F. R. (2004). Postnatal stress in mice: does "stressing" the mother have the same effect as "stressing" the pups? Dev. Psychobiol. 44, 230-237.

Moles, A., Sarli, C., Bartolomucci, A., and D'Amato, F. R. (2008). Interaction with stressed mothers affects corticosterone levels in pups after reunion and impairs the response to dexamethasone in adult mice. Psychoneuroendocrinology 33, 462-470.

Mousseau, T. A., and Fox, C. W. (1998). The adaptive significance of maternal effects. Trends Ecol. Evol. 13, 403.

Munafò, M. R., Brown, S. M., and Hariri, A. R. (2008). Serotonin 
transporter (5-HTTLPR) genotype and amygdala activation: a metaanalysis. Biol. Psychiatry 63, 852-857.

Murphy, D. L., and Lesch, K. P. (2008). Targeting the murine serotonin transporter: insights into human neurobiology. Nat. Rev. Neurosci. 9, 85-96.

Murphy, D. L., Li, Q., Engel, S., Wichems, C., Andrews, A., Lesch, K. P., and Uhl, G. (2001). Genetic perspectives on the serotonin transporter. Brain Res. Bull. 56, 487-494.

Parfitt, D. B., Walton, J. R., Corriveau, E. A., and Helmreich, D. L. (2007). Early life stress effects on adult stress-induced corticosterone secretion and anxietylike behavior in the C57BL/6 mouse are not as robust as initially thought. Horm. Behav. 52, 417-426.

Perrigo, G., Belvin, L., Quindry, P., Kadir, T., Becker, J., van Look, C., Niewoehner, J., and vom Saal, F. S. (1993). Genetic mediation of infanticide and parental behavior in male and female domestic and wild stock house mice. Behav. Genet. 23, 525-531.

Pezawas, L., Meyer-Lindenberg, A., Drabant, E. M., Verchinski, B. A., Munoz, K. E., Kolachana, B. S., Egan, M. F., Mattay, V.S., Hariri, A. R., and Weinberger, D. R. (2005). 5HTTLPR polymorphism impacts human cingulate-amygdala interactions: a genetic susceptibility mechanism for depression. Nat. Neurosci. 8 , 828-834.

Pryce, C. R., and Feldon, J. (2003). Longterm neurobehavioural impact of the postnatal environment in rats: manipulations, effects and mediating mechanisms. Neurosci. Biobehav. Rev. 27, 57-71.

Qvarnström, A., and Price, T. D. (2001). Maternal effects, paternal effects and sexual selection. Trends Ecol. Evol. 16, 95-100.

Rice, W. R. (1989). Analyzing tables of statistical tests. Evolution 43, 223-225.
Richardson, H. N., Zorrilla, E. P., Mandyam, C. D., and Rivier, C. L. (2006). Exposure to repetitive versus varied stress during prenatal development generates two distinct anxiogenic and neuroendocrine profiles in adulthood. Endocrinology 147, 2506-2517.

Risch, N., Herrell, R., Lehner, T., Liang, K. Y., Eaves, L., Hoh, J., Griem, A., Kovacs, M., Ott, J., and Merikangas, K. R. (2009). Interaction between the serotonin transporter gene (5-HTTLPR), stressful life events, and risk of depression: a meta-analysis. J. Am. Med. Assoc. 301, 2462-2471.

Romeo, R. D., Mueller, A., Sisti, H. M. Ogawa, S., McEwen, B. S., and Brake, W. G. (2003). Anxiety and fear behaviors in adult male and female C57BL/6 mice are modulated by maternal separation. Horm. Behav. 43, 561-567.

Schinka, J. A., Busch, R. M., and Robichaux-Keene, N. (2004). A metaanalysis of the association between the serotonin transporter gene polymorphism (5-HTTLPR) and trait anxiety. Mol. Psychiatry 9, 197-202.

Seckl, J. R. (2004). Prenatal glucocorticoids and long-term programming. Eur. J. Endocrinol. 151(Suppl. 3), U49-U62.

Seckl, J. R. (2008). Glucocorticoids, developmental 'programming' and the risk of affective dysfunction. Prog. Brain Res. 167, 17-34.

Seidenbecher, T., Laxmi, T. R., Stork, O., and Pape, H.-C. (2003). Amygdalar and hippocampal theta rhythm synchronization during fear memory retrieval. Science 301, 846-850.

Spinelli, S., Schwandt, M. L., Lindell, S. G., Newman, T.K., Heilig, M., Suomi, S. J., Higley, J. D., Goldman, D., and Barr, C. S. (2007). Association between the recombinant human serotonin transporter linked promoter region polymorphism and behavior in rhesus macaques during a separation paradigm. Dev. Psychopathol. 19, 977-987.

Tjurmina, O. A., Armando, I., Saavedra, J. M., Goldstein, D. S., and Murphy, D. L. (2002). Exaggerated adrenomedullary response to immobilization in mice with targeted disruption of the serotonin transporter gene. Endocrinology 143, 4520-4526.

Treit, D., and Fundytus, M. (1988). Thigmotaxis as a test for anxiolytic activity in rats. Pharmacol. Biochem. Behav. 31, 959-962.

Vallée, M., Mayo, W., Dellu, F., Le Moal, M. Simon, H., and Maccari, S. (1997). Prenatal stress induces high anxiety and postnatal handling induces low anxiety in adult offspring: correlation with stress-induced corticosterone secretion. J. Neurosci. 17, 2626-2636.

Veenema, A. H., Bredewold, R., and Neumann, I. D. (2007). Opposite effects of maternal separation on intermale and maternal aggression in C57BL/6 mice: link to hypothalamic vasopressin and oxytocin immunoreactivity. Psychoneuroendocrinology 32, 437-450.

vom Saal, F. S., and Howard, L. S. (1982) The regulation of infanticide and parental behavior: implications for reproductive success in male mice. Science 215, 1270-1272.

Ward, H. E., Johnson, E. A., Salm, A. K. and Birkle, D. L. (2000). Effects of prenatal stress on defensive withdrawal behavior and corticotropin releasing factor systems in rat brain. Physiol. Behav. 70, 359-366.

Weber, E. M., and Olsson, I. A. S. (2008) Maternal behaviour in Mus musculus sp.: an ethological review. Appl. Anim. Behav. Sci. 114, 1.

Weinstock, M. (2005). The potential influence of maternal stress hormones on development and mental health of the offspring. Brain Behav. Immun. 19, 296-308.

Weinstock, M. (2008). The long-term behavioural consequences of prenatal stress. Neurosci. Biobehav. Rev. 32, 1073-1086.

Wellman, C. L., Izquierdo, A., Garrett, J. E., Martin, K. P., Carroll, J., Millstein, R., Lesch, K.-P., Murphy, D. L., and Holmes, A. (2007). Impaired stresscoping and fear extinction and abnormal corticolimbic morphology in serotonin transporter knock-out mice. J. Neurosci. 27, 684-691.

Zhao, S., Edwards, J., Carroll, J. Wiedholz, L., Millstein, R.A., Jaing, C., Murphy, D. L., Lanthorn, T. H., and Holmes, A. (2006). Insertion mutation at the C-terminus of the serotonin transporter disrupts brain serotonin function and emotion-related behaviors in mice. Neuroscience 140, 321-334.

Conflict of Interest Statement: The authors declare that the research was conducted in the absence of any commercial or financial relationships that could be construed as a potential conflict of interest.

Received: 30 June 2009; paper pending published: 14July 2009; accepted: 19August 2009; published online: 09 September 2009.

Citation: Heiming RS, Jansen F, Lewejohann L, Kaiser S, SchmittA, Lesch KP and SachserN (2009) Living in a dangerous world: the shaping of behavioral profile by early environment and 5-HTT genotype. Front. Behav. Neurosci. 3:26. doi: 10.3389/neuro.08.026.2009 Copyright (c) 2009 Heiming, Jansen, Lewejohann, Kaiser, Schmitt, Lesch and Sachser. This is an open-access article subject to an exclusive license agreement between the authors and the Frontiers Research Foundation, which permits unrestricted use, distribution, and reproduction in any medium, provided the original authors and source are credited. 